\title{
LADC-6087 (Pablication Version)
}

OCMan 301964

MASTER 81330

CONTRIBUTION FROM THE LOS ALAMOS SCIENTIFIC LABORATORY

UNIVERSITY OF CALIFORNIA, LOS ALAMOS, NEW MEXICO

1 Preparation and Crystal Data for Lanthanide and Actinide Tri-Iodides 1

By L. B. ASPREY, T. K. KEENAN, AND F. H. KRUSE

Received

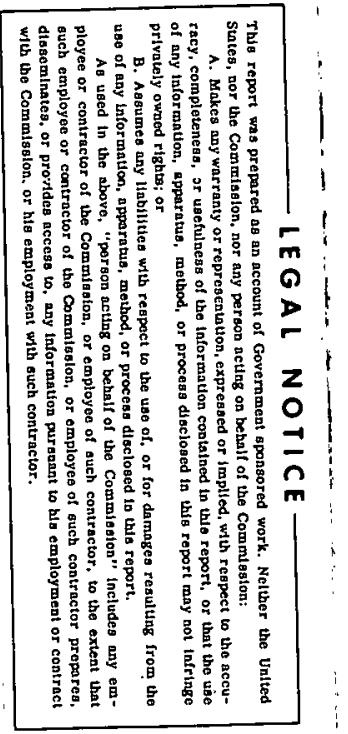

Lattice parameters and crystal structure types for twelve lanthanide tri-iodides (excepting only promethium and europium) have been determined. Similar data have been obtained for yttrium, americium, and plutonium tri-iodides. Two structure types occur in the lanthanide tri-iodides. The lighter members, $\mathrm{LaI}_{3}$ through $\mathrm{NdI}_{3}$, have orthorhombic symmetry $\left(\mathrm{PuBr}_{3}\right.$ type) while the heavier members of the series are hexagonal $\left(\mathrm{BiI}_{3}\right.$ type). An analogous transition is observed in the actinide series between $\mathrm{PuI}_{3}$ and $\mathrm{AmI}_{3}$, the former being orthorhombic and the latter hexagonal. Treatment of $\mathrm{AmI}_{3}$ with hydrogen at elevated temperatures gave no evidence of a divalent. compound of americium.

\section{Introduction}

Though most of the lanthanide and many actinide trifluorides, trichlorides, and tribromides have been prepared and identified, few investigations of the chemistry of the corresponding tri-iodides have been published. The tri-iodides of lanthanum, neodymium, uranium, neptunium, plutonium, and americium were 2,3 reported to have an orthorhombic structure. ${ }^{2}$ Druding and Corbett ${ }^{3}$ stated that - $\mathrm{NdI}_{3}$ underwent a phase transition from orthorhombic to hexagonal at $574^{\circ}$; this 


\section{DISCLAIMER}

This report was prepared as an account of work sponsored by an agency of the United States Government. Neither the United States Government nor any agency Thereof, nor any of their employees, makes any warranty, express or implied, or assumes any legal liability or responsibility for the accuracy, completeness, or usefulness of any information, apparatus, product, or process disclosed, or represents that its use would not infringe privately owned rights. Reference herein to any specific commercial product, process, or service by trade name, trademark, manufacturer, or otherwise does not necessarily constitute or imply its endorsement, recommendation, or favoring by the United States Government or any agency thereof. The views and opinions of authors expressed herein do not necessarily state or reflect those of the United States Government or any agency thereof. 


\section{DISCLAIMER}

Portions of this document may be illegible in electronic image products. Images are produced from the best available original document. 
4,5 was confirmed by Dworkin and Bredig. ${ }^{4}$ Another study by Krause et al. , 5 indicated that $\mathrm{YI}_{3}$ has the hexagonal $\mathrm{BiI}_{3}$ structure type.

Previous studies of the lanthanide trihalides show that a change in structure type takes place near the midpoint of the series. Such a change

$6 ; 7,8,9$ is observed in the lanthanide trifluorides, ${ }^{6}$ trichlorides, $^{7,8}$ and tribromides, 2,9 although complete crystallographic data has not always been reported for all members of the series of a given trihalide. Of the actinide trihalides which have been reported, a change in structure type has been noted. only for the tribromides. The transition occurs at neptunium tribromide which is dimorphic; $\alpha-\mathrm{NpBr}_{3}$ shows hexagonal symmetry while $\beta-\mathrm{NpBr}_{3}$ is orthorhombic. ${ }^{2,9}$ In order to expand our knowledge of these transitions and the related chemistry of tri-iodides, it was decided to prepare as many as possible of the lanthanide and actinide tri-iodides. With the latter, micro-scale preparations were necessary because of radiation and health hazards.

\section{Experimental}

General. - Unless otherwise stated, all chemicals were "AR" grade and used without further purification. The lanthanide metals were obtained from various sources, including Lindsay Rare Earth Chemicals, Semi-Elements, Inc., and Research Chemicals Company, and exceeded 99.5\% purity. Plutonium metal of $>99.5 \%$ purity was available at. Los Alamos. (Plutonium supplied by Joseph Leary of this laboratory.) Americium stock solutions contained $<0.5 \%$ total cation impurity. Tank hydrogen was purified by passage through a heated silver-palladium alloy valve prior to use.

Several methods are available to prepare anhydrous lanthanide halides. 10,11, 12 These are summarized in several recent review papers, $10,11,12$ However, we found that a technique described by Asprey and Kruse ${ }^{13}$ gave excellent 
results with relative ease of manipulation. This method involves the reaction of a lanthanide metal with mercuric iodide, i.e.,

$2 \mathrm{Ln}$ (any lanthanide metal) $+3 \mathrm{HgI}_{2} \stackrel{\Delta}{\longrightarrow} 2 \mathrm{LnI}_{3}+3 \mathrm{Hg}$. In addition to yielding an excellent tri-iodide product, the principal advantages of this method are: (1) the reactant, $\mathrm{HgI}_{2}$, is stable at room temperature and can be weighed in air, and (2) the by-product $\mathrm{Hg}$ can easily be separated by distillation from the tri-iodide.

Preparation of $\mathrm{LaI}_{3}, \mathrm{CeI}_{3}, \mathrm{PrI}_{3}, \mathrm{NdI}_{3}, \mathrm{GdI}_{3}, \mathrm{TbI}_{3}, \mathrm{HoI}_{3}, \mathrm{ErI}_{3}, \mathrm{TmI}_{3}$, $\mathrm{LuI}_{3}, \mathrm{YI}_{3}$, and $\mathrm{PuI}_{3}$ by the Reaction of $\mathrm{HgI}_{2}$ with the Metallic Element. - In a typical run, ca. $0.2-0.5$ mmole of the reactant metal was used with a slight deficiency of $\mathrm{HgI}_{2}$ (ca. 99\% of theoretical). The two reactants were placed in a $7 \times 50 \mathrm{~mm}$. quartz tubo whioh was ovacuated to oa. $5 \times 10^{-6} \mathrm{~mm}$. and sealed. The tube was placed in a muffle furnace; the temperature was slowly raised and held at $500^{\circ}$ for two hours, followed by slow cooling for eight hours. The absence of the orange-red $\mathrm{HgI}_{2}$. indicated completion of the reaction. One end of the tube was then placed in a small furnace to distill free mercury from the desired tri-iodide product. The tube was transferred to an inert-atmosphere (helium) glove box, opened, the tri-iodide ground in a mortar, and an X-ray capillary loaded. In the experiment involving plutonium, all such operations were carried out in a conventional radiochemical glove box containing an inner polyethylene bag with integral glove forms. ${ }^{14}$ Dry helium was used to flush oxygen and water vapor from this device prior to opening the reaction tube.

Preparation of $\mathrm{SmI}_{3}, \mathrm{YbI}_{3}$, and Attempted Preparation of $\mathrm{EuI}_{3}$ by the Reaction of the Metallic Element with Elemental Iodine. - The reaction with $\mathrm{HgI}_{2}$ was not satisfactory when used with samarium, ytterbium, and europium. It was necessary to utilize the thermodynamically more favorable system involving direct reaction of the lanthanide metal with iodine. In a typical run, 
0.5 mmole of metal was placed in a heavy-walled quartz reaction tube. This tube was formed from $10 \mathrm{~mm}$. quartz tubing having a wall thickness of $2.5 \mathrm{~mm}$. An amount of iodine required to give the desired pressure at the experimental temperature was then introduced. The equilibrium pressure was estimated, assuming ideal gas behavior from the known volume of the tube and the observed temperature. With the iodine cooled in an ice bath, the reaction tube was evacuated to $0.001 \mathrm{~mm}$. and sealed off. For protection against possible explosion or implosion, the quartz tube was placed in a steel pipe capped at both ends with a vented cover. The tube assembly was placed in a muffle furnace.

Following a run, the excess iodine was distilled to one end of the tube by warming the opposite end. The reaction tube was transferred to the inert atmosphere box, opened, and the product removed. The sample was ground to a fine powder and an X-ray capillary prepared as before.

The following conditions were found adequate to yield satisfactory samples of samarium and ytterbium:

Samarium: Slow heating to $500^{\circ}$ over 8 hours, holding at $500^{\circ}$ for two hours with an iodine pressure of $5 \mathrm{~atm}$ at $500^{\circ}$.

Ytterbium: Slow heating to $500^{\circ}$ over 8 hours, holding at $500^{\circ}$ for sixteen hours with an iodine pressure of $30 \mathrm{~atm}$ at $500^{\circ}$ 。

Similar experiments with europium, involving temperatures as high as $600^{\circ}$ and pressures of $100 \mathrm{~atm}$ of iodine gave an unidentified product not isostructural with other lanthanide tri-iodides.

Preparation of $\mathrm{AmI}_{3}$ by the Reaction of $\mathrm{AmCl}_{3}$ with $\mathrm{NH}_{4} \mathrm{I}$. - Americium tri-iodide was not prepared by either of the previous methods because of the difficulty in obtaining pure americium metal. Using an X-ray capillary as a container, the metathetical reaction, $\mathrm{AmCl}_{3}+3 \mathrm{NH}_{4} \mathrm{I}-\Delta \mathrm{AmI}_{3}+3 \mathrm{NH}_{4} \mathrm{Cl}$, was carried out in situ using a flow system to sweep the volatile $\mathrm{NH}_{4} \mathrm{Cl}$ away from the tri-iodide. 
The starting material was an anhydrous mixture of $\mathrm{AmCl}_{3}$ in a matrix of $\mathrm{NH}_{4} \mathrm{Cl}$. This was obtained by evaporation of an $\mathrm{HCl}$ solution containing a 10:1 mole ratio of $\mathrm{NH}_{4} \mathrm{Cl}: \mathrm{AmCl}_{3}$. Such a salt mixture is quite stable in air and may be ground and handled without deliquescence. After preparation and grinding a small quantity of this material ca. 50 micrograms americium) was introduced into a quartz capillary, which was drawn from an 18/9 semi-ball joint. Fig. 1 shows a diagram of the experimental apparatus. The furnace was mounted on wheels and could be moved as desired. A large excess of $\mathrm{NH}_{4} \mathrm{I}$ was added to the tube containing the $\mathrm{NH}_{4} \mathrm{Cl} / \mathrm{AmCl}_{3}$ mixture and the joint sealed with Api ezon-W to the vacuum manifold. The system was evacuated to $<5 \times 10^{-6} \mathrm{~mm}$. The furnace was placed around the sample and held at $100-130^{\circ}$ for one hour under vacuum to remove any residual moisture. The system was then pressurized with hydrogen to ca. 3 p.s.1. and the tip of the capi llary was clipped with a scissors. (The samples adhered to the capillary and usually did not blow out the open tip in the hydrogen stream.) The furnace was heated to $400^{\circ}$ and moved slowly upstream from the open tip. The $\mathrm{NH}_{4} \mathrm{Cl}$ was sublimed away first from the $\mathrm{NH}_{4} \mathrm{Cl} / \mathrm{AmCl}_{3}$ mixture and then the $\mathrm{NH}_{4} \mathrm{I}$ was sublimed over the $\mathrm{AmCl}_{3}$, converting it to the tri-iodide. After the $\mathrm{NH}_{4} \mathrm{I}$ was removed the hydrogen pressure was lowered to slightly over atmospheric, the open tip of the capillary was sealed with a torch and the system evacuated again. The furnace was again placed around the sample and heated to $400^{\circ}$ to insure that any residual ammonium halide was sublimed away from the americium tri-iodide. The capillary was sealed under vacuum and removed for X-ray analysis. Very little trouble was experienced with alpha activity on the outside of such capillaries.

X-ray Diffraction Techniques. - In all cases, the tri-iodide products were identified by $\mathrm{X}$-ray powder diffraction photographs. Diffraction equipment included a basic Norelco X-ray unit using filtered copper radiation, $114.6 \mathrm{~mm}$. 
Debye-Scherrer cameras and Ilford type "G" film. Since the structure type for each tri-iodide was known or could be postulated, it was possible to compute a

Gk. theta typical pattern ( $h k l, I_{0}, 2 \theta$, d spacing) for indexing the X-ray patterns. Subsequently, another computer program was employed to obtain a least-squares refinement of the lattice dimensions. Normally, the two cycles with these programs sufficed to give the final parameters. The powder pattern generating program was the POWD code supplied by Smith; ${ }^{15}$ the least-squares program was the MET-124 code supplied by Mueller and Heaton. ${ }^{16}$ Both programs were used on an IBM-7094 computer.

\section{Results}

Analysis of the powder diffraction data shows that every lanthanide and actinide iodide examined falls into one of two structure types. The lighter lanthanide and actinide tri-iodides are orthorhombic, $\mathrm{PuBr}_{3}$ structure type. 9 The tri-iodides of the heavier members of the series are hexagonal, $\mathrm{BiI}_{3}$ structure type. ${ }^{5}$ The change in structure type from orthorhombic to hexagonal takes place between neodymium and samarium tri-iodides in the lanthanide series and between plutonium and americium tri-iodides in the actinide series. Table I lists lattice constants and molecular volumes for the compounds studied; the error limits shown are standard deviations. Partial powder X-ray diffraction patterns for typical orthorhombic $\left(\mathrm{CeI}_{3}\right)$ and hexagonal $\left(\mathrm{DyI}_{3}\right)$ types are presented in Table II. The variation in molecular volume with atomic number for several lanthanide and actinide halides, including the present work, are plotted in Figs. 2 and 3. It can be seen that a change in 'structure type is generally exhibited by all of these compounds.

No evidence was obtained for the preparation of an orthorhombic $\mathrm{AmI}_{3}$ phase as reported some years ago ${ }^{2}$ (no details were given for the preparation of that americium compound). In any event, under widely 'varying conditions, we always obtained $\mathrm{AmI}_{3}$ of hexagonal symmetry. No evidence was obtained for divalent americium. Under conditions which produced $\mathrm{SmI}_{2}, \mathrm{EuI}_{2}$, and 
$\mathrm{YbI}_{2}$, only hexagonal $\mathrm{AmI}_{3}$ was prepared. Some evidence was also obtained for the expected hexagonal symmetry in $\mathrm{CmI}_{3}$. However, a more complete study of the halides of americium and curium is currently under way in this laboratory and the results will be announced in the near future.

The high pressure $I_{2}$ experiments with europium did not give a product whose X-ray powder pattern could be indexed as either the orthorhombic or hexagonal forms of tri-iodide. Either $\mathrm{EuI}_{\mathbf{g}}$ was not formed or, less likely, it has a new and different structure. In Table I the molecular volume of the hexagonal compound, $\mathrm{SmI}_{3}$, is $168.4 \AA^{3}$, somewhat less than that of $\mathrm{GdI}_{3}$. This suggests that the $\mathrm{SmI}_{8}$ compound may have contained some $\mathrm{SmI}_{2}$ in solid solution, or the lower value may. be due to effects yet unidentified. 
$\underline{\text { Table I }}$

Lattice Constants and Molecular Volumes of Some Lanthanide and Actinide Tri-Iodides

1. Structure Type $\mathrm{PuBr}_{3}$

Orthorhombic; $n=4 ;$ Space Group: $C \mathrm{cmm}-\mathrm{D}_{2 \mathrm{~h}}^{1}$

\begin{tabular}{|c|c|c|c|c|c|c|c|}
\hline Compound & & , $\AA$ & & $\AA$ & $c_{Q^{\prime}}$ & $\AA$ & Mol. Vol. \\
\hline $\mathrm{LaI}_{3}$ & 4.37 & \pm 0.02 & 14.01 & \pm 0.02 & 10.04 & \pm 0.01 & 153.6 \\
\hline $\mathrm{CeI}_{3}$ & 4.341 & \pm 0.008 & 14.00 & \pm 0.01 & 10.015 & \pm 0.004 & 152.2 \\
\hline $\mathrm{PrI}_{3}$ & 4.309 & \pm 0.008 & 13.98 & \pm 0.01 & 9.958 & \pm 0.008 & 150.0 \\
\hline $\mathrm{NdI}_{3}$ & 4. 284 & \pm 0.004 & 13.979 & $\pm 0,008$ & 9.948 & \pm 0.004 & 148.9 \\
\hline $\mathrm{PuI}_{3}$ & 4.33 & \pm 0.02 & 13.95 & \pm 0.03 & 9.96 & \pm 0.02 & 150.4 \\
\hline
\end{tabular}

2. Structure Type $\mathrm{BiI}_{\mathrm{g}}$

Hexagonal; $\mathbf{n}=6$; Space Group: $\mathbf{R} \overline{3}-\mathbf{C}_{31}^{2}$ Hexagonal Dimension 8
Rhombohedral

Dimensions

Gk. alpha

Comp

\section{(20)}

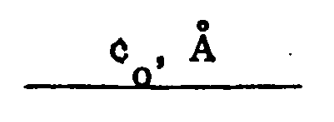

$7.490 \pm 0.008$

$20.80 \pm 0.04$

$\underline{a_{0}(\mathrm{rh}) \stackrel{\circ}{\mathrm{A}} \alpha^{\circ}(\mathrm{rh})}$

8.172

54.44

8.196

54.77

8.193

54.68

8.179

54.48

8.171

54.43

8.155

54.37

8.141

54.18

8.132

54.40

8.117

54.20

8.08

54.67

8.198

54.48

Mol. Vol. $\AA^{\text {s }}$

168.4 ;

170.8

170.4

168.6

167.8

166.5

164.9

165.3

$\mathrm{LuI}_{3}$

$7.395 \pm 0.00820 .71 \pm 0.02$

$20.55 \pm 0.08$

$7.505 \pm 0.00420 .88 \pm 0.01$

8.198

163.5

$\mathrm{YI}_{\mathrm{g}}$ 


\section{Table II}

Partial Powder X-Ray Patterns

A. $\mathrm{CeI}_{3}-$ Orthorhombic $\left(\mathrm{PuBr}_{3}\right.$ Type)

$\frac{\mathrm{hk} \ell}{020} \quad \frac{\mathrm{d} \text { obs } \AA}{6.93} \quad \frac{\mathrm{d} \text { calc } \AA}{6.99} \quad \frac{\mathrm{I} / \mathrm{I}_{0}}{4}$

$\begin{array}{llll}040 & 3.48 & 3.49 & 2\end{array}$

$\begin{array}{llll}041 & 3.29 & 3.30 & 3\end{array}$

$\left.\begin{array}{l}112 \\ 130\end{array}\right\} \quad 3.19 \quad\left\{\begin{array}{l}3.18 \\ 3.17\end{array}\right\} \quad 7$

$\begin{array}{llll}131 & 3.030 & 3.022 & 10\end{array}$

$\begin{array}{llll}023 & 3.000 & 3.002 & 9\end{array}$

$\begin{array}{llll}042 & 2.860 & 2.861 & 6\end{array}$

$132 \quad 2.680 \quad 2.676 \quad 2$.

$\begin{array}{llll}113 & 2.601 & 2.591 & 6\end{array}$

$\begin{array}{llll}004 & 2.498 & 2.494 & 2\end{array}$

$\begin{array}{llll}024 & 2.351 & 2.348 & 1\end{array}$

$\left.\begin{array}{c}133 \\ 151\end{array}\right\} \quad 2.296 \quad\left\{\begin{array}{l}2.295 \\ 2.285\end{array}\right\} \quad 4$

$061 \quad 2.266 \quad 2.267 \quad 2$

$\begin{array}{llll}200 & 2.179 & 2.166 & 4\end{array}$

$152 \quad 2.130 \quad 2.124 \quad 1$

$0622.111^{\prime} \quad 2.110 \quad 7$
B. DyI $_{3}-$ Hexagonal (BiI 3 Type)

$\underline{\mathrm{hk} \ell} \underline{\mathrm{d} \text { obs } \AA}$ d calc $\AA \quad \mathrm{I} \mathrm{I}_{0}{ }^{*}$

$\begin{array}{llll}003 & 7.00 & 6.88 & 4\end{array}$

$\left.\begin{array}{l}015 \\ 006\end{array}\right\} \quad 3.46 \cdot\left\{\begin{array}{l}3.51 \\ 3.47\end{array}\right\} \quad 5$

$\begin{array}{llll}113 & 3.29 & 3.30 & 10\end{array}$

$1162.54,2.55 \quad 8$

$122 \cdots 2.31 \quad 2.39 \quad 1$

$\begin{array}{llll}300 & 2.165 & 2.166 & 6\end{array}$

$\begin{array}{llll}303 & 2.068 & 2.067 & 2\end{array}$

$\begin{array}{llll}119 & 1.968 & 1.969 & 9\end{array}$

$\begin{array}{llll}306 & 1.837 & 1.837 & 3\end{array}$

$223 \quad 1.810 \quad 1.811 \quad 4$

$\begin{array}{llll}00 \cdot 12 & 1.736 & 1.735 & 6\end{array}$

$226 \quad 1.651 \cdot 1.650 \quad 4$

$\begin{array}{llll}039 & 1.580 & 1.581 & 1\end{array}$

$229 \quad 1.458 \quad 1.457 \quad 3$

$413 \quad 1.389 \quad 1.389 \quad 4$

$30 \cdot 12 \quad 1.355 \quad . .1 .354 \quad 5$

* Relative visual intensities based on scale of 10 as maximum. 
- $\quad-10-$

.

Figure 1 - Apparatus for Preparation of Actinide Tri-Iodides. 


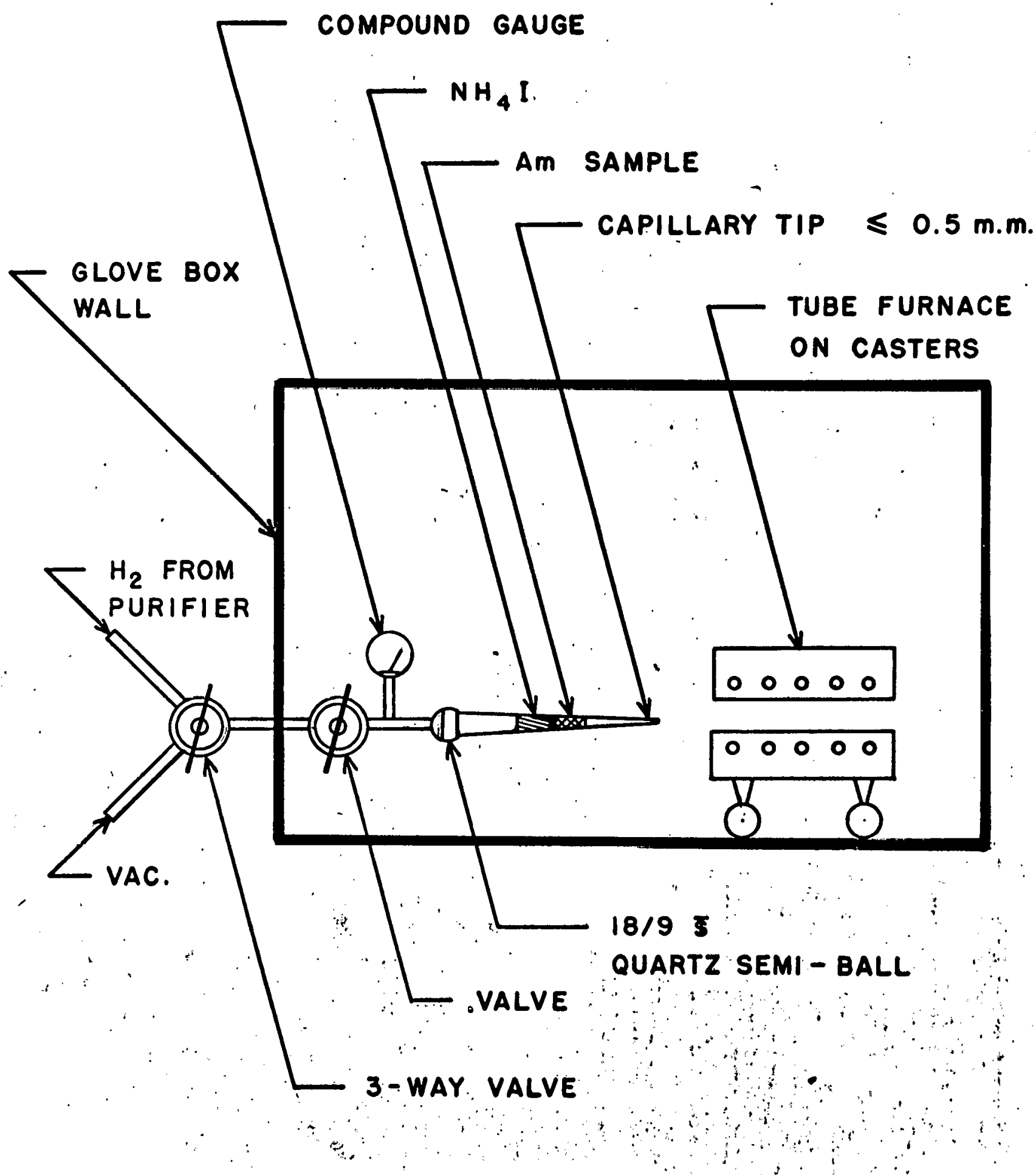


$-11-$

Figure 2 - Variation of Molecular Volume with Atomic Number for Lanthanide Trihalides. 


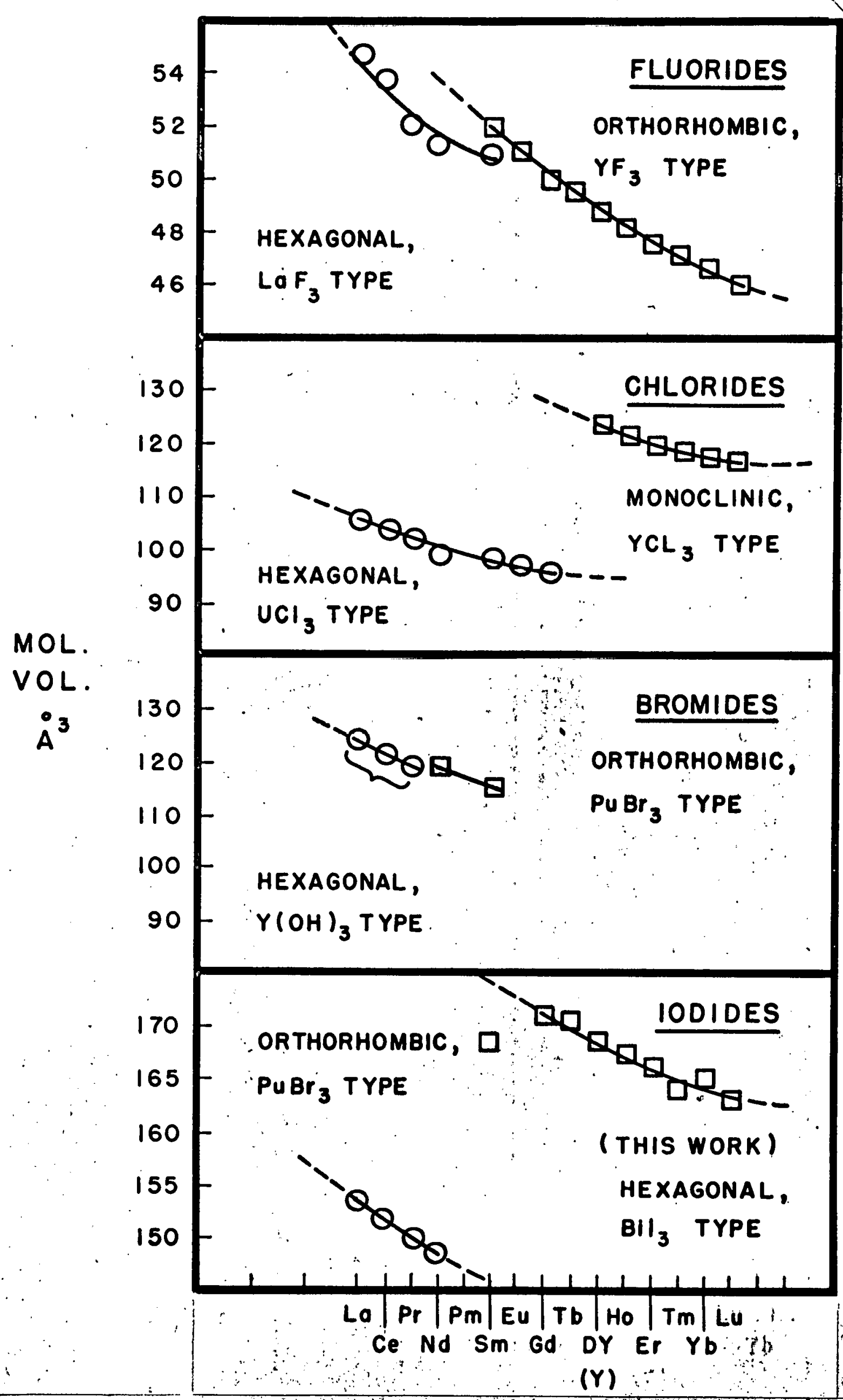


Figure 3 - Variation of Molecular Volume with Atomic Number for Actinide Trihalides. 


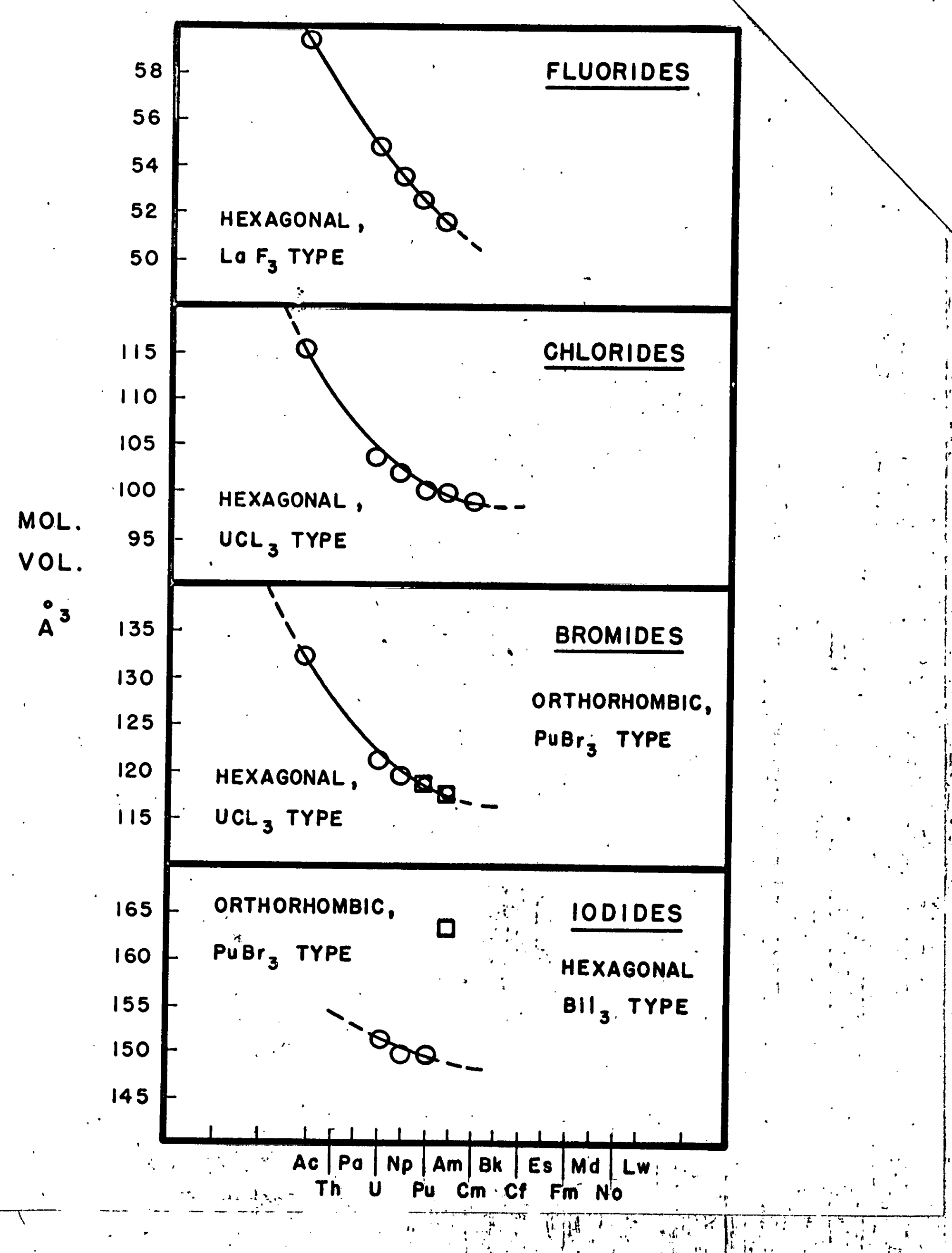




\section{References}

1. Work performed under the auspices of the U. S. Atomic Energy Commission.

2. W. H. Zachariasen, Acta Cryst., 1; 265 (1948).

3. L. F. Druding and J. D. Corbett, J. Am. Chem. Soc., 83, 2462 (1961).

4. A. S. Dworkin and M. A. Bredig, J. Phys. Chem., 67, 697 (1963).

5. B. H. Krause, A. B. Hook, and F. Wawner, Acta Cryst., 16, 848 (1963).

6. A. Zalkin and D. H. Templeton, J. Am. Chem. Soc., 75, 2453 (1953).

7. D. H. Templeton and G. F. Carter, J. Phys. Chem., 58, 940 (1954).

8. D. H. Templeton and C. H. Dauben, J. Am. Chem. Soc., 76, 5237 (1954) .

9. A. J. C. Wilson, "Structure Reports", Oosthoek, Utrecht, Netherlands, Vol. 11, p. 276 and 282 (1948).

10. M. D. Taylor, Chem. Rev, , 62, 503 (1962) .

11. M. D. Taylor and C. P. Carter, J. Inorg. Nucl. Chem., 24, 387 (1962).

12. N. H. Kiess, J. Research Nat'1. Bureau Standards, 67A, 343 (1963).

13. L. B. Asprey and F. H. Kruse, J. Inorg. Nucl. Chem., 13, 32 (1960).

14. This is a polyethylene bag with molded glove forms with appropriate provision for entry and escape of gas. They are manufactured by Instruments for Research and Industry, Cheltenham, $\mathrm{Pa}$.

15. D. K. Smith, "A Fortran Program for Calculating X-ray Powder Diffraction Patterns", University of California Report UCRL-7196 (1963).

16. M. H. Mueller and L. Heaton, "Determination of Lattice Parameters with the Aid of a Computer", Argonne National Laboratory Report ANL-6176 (1961). 


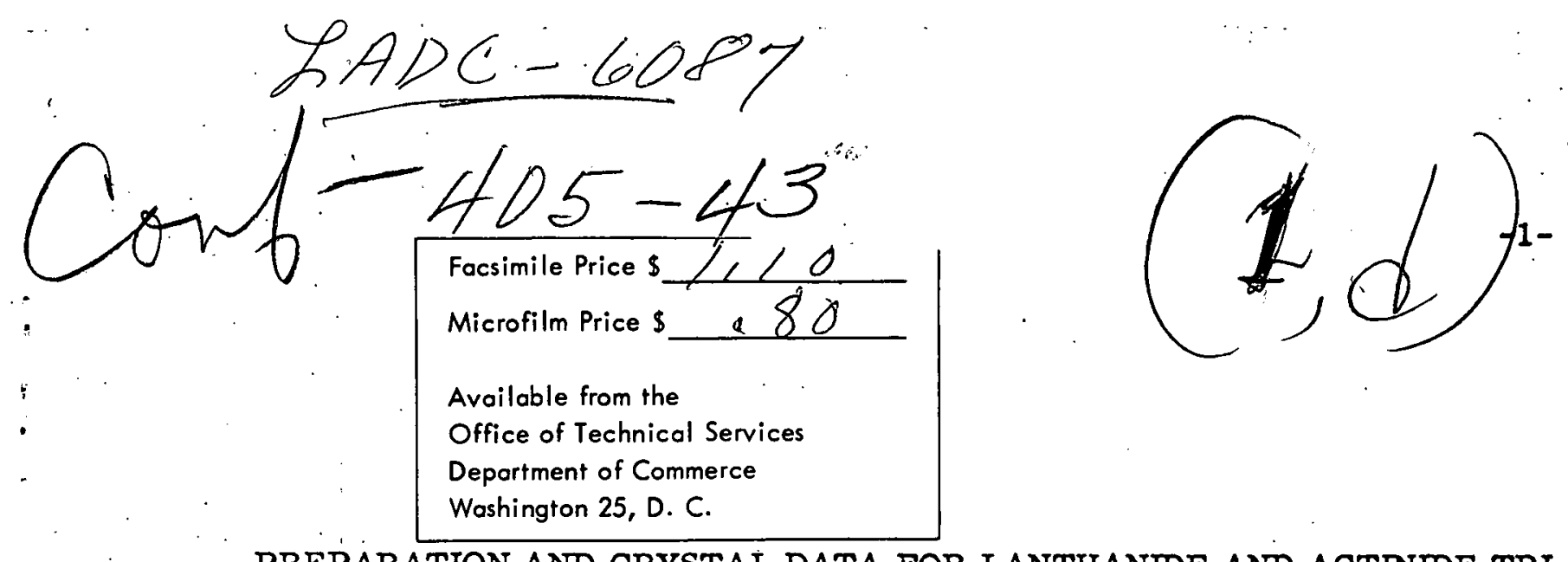

PREPARATION AND CRYSTAL DATA FOR LANTHANDE AND ACTINDE TRI-IODIEES*

T. K. Keenan, L. B. Asprey and F. H. Kruse

Los Alamos Scientific Laboratory, Los Alamos, New Mexico

\section{Introduction}

There is rather meager information in the literature concerning crystal structures, lattice constants, etc., of the lanthanide and actinide iodides. The tri-iodides of lanthanum, neodymium, uranium, neptunium, plutonium, and americium were reported to have an orthorhombic structure. ${ }^{1}$ Druding and Corbett ${ }^{2}$ stated that $\mathrm{NdI}_{3}$ underwent a phase transition from or thorhombic to hexagonal at $574^{\circ}$; this was confirmed by Dworkin and Bredig ${ }^{3}$. Another study by Krause, et al. ${ }^{4}$, indicated that $\mathrm{YI}_{s}$ has the hexagonal $\mathrm{BiI}_{8}$ structure type.

Previous studies of the lanthanide trihalides show that a change in structure type takes place slightly before the midpoint of the series. Such a change is observed in the lanthanide trifluorides ${ }^{5}$, trichlorides 6,7 , and tribromides ${ }^{1,8}$, although complete crystallographic data has rarely been reported for all members of the series of a given trihalide. Of the actinide trihalides that

1. W. H. Zachariasen, Acta Cryst., 1,265 (1948)

2. L. F. Druding and J. D. Corbett, J. Am. Chem. Soc., 83, 2462 (1961)

3. A. S. Dworkin and M. A. Bredig, J. Phys. Chem., 67, 697 (1963)

4. B. H. Krause, A. B. Hook, and F. Wawner, Acta Cryst., 16, 848 (1963)

5. A. Zalkin and D. H. Templeton, J. Am. Chem. Soc., 75, 2453 (1953)

6. D. H. Templeton and G. F. Carter, J. Phys. Chem., 58, 940 (1954)

7. D. H. Templeton and C. H. Dauben, J. Am. Chem. Soc., 76, 5237 (1954)

8. A. J. C. Wilson, "Structure Reports", Oosthoek, Utrecht, Netherlands, Vol. 11, pp. 276 and 282 (1948)

*Work done under the auspices of the U. S. Atomic Energy Commission. 
i

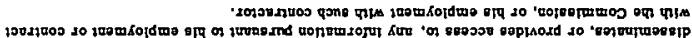

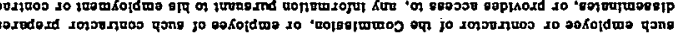

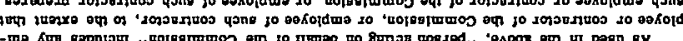

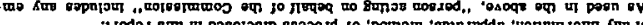

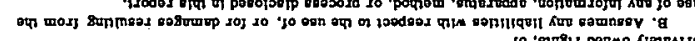

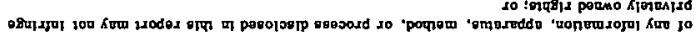

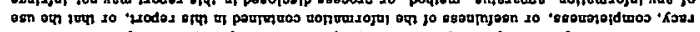

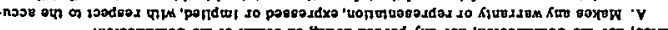

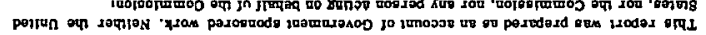
3JIION TVO3T 